\title{
PERBANDINGAN HASIL PRODUKSI SUMUR FA \#17 SEBELUM DAN SETELAH WELL SERVICE DENGAN MENGGUNAKAN METODE BAILING OUT SAND DI PT PERTAMINA HULU ENERGI SIAK FIELD BATANG
}

\author{
Diky Pranondo, Faathir Xevino Viedin \\ Program Studi Teknik Eksplorasi Produksi Migas, Jurusan Teknik Perminyakan \\ Politeknik Akamigas Palembang
}

\begin{abstract}
Abstrak : Beberapa Sumur di Lapangan Batang PT Pertamina Hulu Energi dengan indikasi intensitas well service yang sangat tinggi. Fenomena FNCO (Fluid Not Coming Out) di lapangan ini sering terjadi perawatan sumur paling tinggi adalah Bailing Out Sand (BOS) akibat kepasiran. Maka dari itu di lakukannya kegiatan well service pada Sumur FA \#17. Pada Sumur FA \#17 sebelum kegiatan well service di lakukan di dapatlah data berdasarkan hasil Plot $\mathrm{P}_{\mathrm{wf}}$ vs $\mathrm{Q}$ pada kurva IPR, di peroleh nillai dari $\mathrm{Q}_{\text {act }}$ sebesar 138,6 bfpd, $\mathrm{Q}_{\max } 570,9667 \mathrm{bpd}$. Kemudian di dapat laju alir fluida sebesar 138,6 bfpd dan laju alir minyak sebesar 76,24 bopd dan untuk PI-nya 4,497 bbl/psi. Setelah kegiatan Well Service di lakukan terjadi perubahan di setiap parameternya yaitu dengan laju alir fluida sebesar 159,2 bfpd dan laju alir minyak sebesar 90,71 bopd. Dilihat dari hasil Plot $\mathrm{P}_{\mathrm{wf}}$ vs $\mathrm{Q}$ pada kurva IPR, diperoleh nilai $\mathrm{Q}_{\text {act }}$ sebesar 159,2 bfpd dan $\mathrm{Q}_{\max }$ sebesar 1179,956 bpd. Lalu untuk PI menjadi 9,586 bbl/psi, sehingga pekerjaan kegiatan well service ini dapat di katakan berhasil karena dari beberapa aspek tersebut mengalami peningkatan.
\end{abstract}

Kata kunci : Gross, $\mathrm{Q}_{\max }, \mathrm{Q}_{\text {act }}$, Productivity Index, Bailing Out Sand (BOS), Well Service.

\section{PENDAHULUAN}

\subsection{Latar Belakang}

PT Pertamina Hulu Energi Siak merupakan anak perusahaan PT Pertamina Hulu Energi yang merupakan KKKS (Kontraktor kontrak kerja sama) dengan daerah operasi di Lapangan Batang dan Lindai di Provinsi Riau. Lapangan Batang memproduksikan minyak dengan kategori minyak berat, viskositas tinggi dan berada pada kedalaman yang dangkal. Oleh karena itu, kepasiran merupakan masalah yang paling umum dijumpai di Lapangan Batang.

Beberapa Sumur di Lapangan Batang dengan indikasi intensitas well service yang tinggi, di karenakan banyaknya pasir di berbagai kedalaman sumur sehingga perlunya dilakukan pekerjaan pengangkatan pasir dengan menggunakan metode Bailing Out Sand. Masalah kepasiran ini muncul sebagai akibat zona produksi berada pada kedalaman yang dangkal sehingga batu pasir tidak terkompaksi dengan baik (un-consolidated sandstone) sehingga runtuh dan terakumulasi di dalam sumur. Akumulasi pasir ini kemudian mengganggu operasi pompa Sucker Rod Pump (SRP) sehingga pekerjaan well service begitu sering dilakukan.

Masalah produksi pasir banyak dijumpai pada lapangan minyak dari lapisan batu pasir produktif di kedalaman dangkal sampai yang dalam. Menurunnya kapasitas produksi dan laju produksi minyak merupakan masalah produksi. Masalah produksi ini harus di identifikasi secara dini untuk dapat di tangani sebelum masalah terjadi maupun setelah terjadi. Penanganan masalah produksi yang tepat akan mengembalikan sumur berproduksi dengan kapasitas yang optimum. 


\subsection{Tujuan Penelitian}

Tujuan yang ingin dicapai dalam pelaksanaan Penelitian ini antara lain :

1. Untuk dapat mengetahui proses dan cara kerja metode bailing out sand pada kegiatan well service.

2. Untuk dapat mengetahui kapasitas sand pump yang digunakan pada Sumur FA \#17.

3. Untuk dapat mengetahui perbandingan hasil produksi sebelum dan setelah Well Service pada sumur FA \#17.

\section{DASAR TEORI}

\subsection{Basic Petroleum System}

Well test sendiri murupakan kegiatan untuk mengetahui karakteristik dari suatu reservoir dengan mencatat perubahan tekanan dan laju alir, namun untuk analisis lebih lanjut dari suatu kegiatan well test perlu ditinjau terhadap segala aspek yang terkait pada Basic Petroleum System, yaitu proses untuk menemukanya kandungan hidrokarbon dibawah permukaan. Di dalam Basic Petroleum

System terdapat

komponenkomponen penting yang harus ada. Komponen-komponen tersebut adalah:
1. Source Rock
2. Reservoir Rock
3. Migrasi
4. Trap
5. Seal

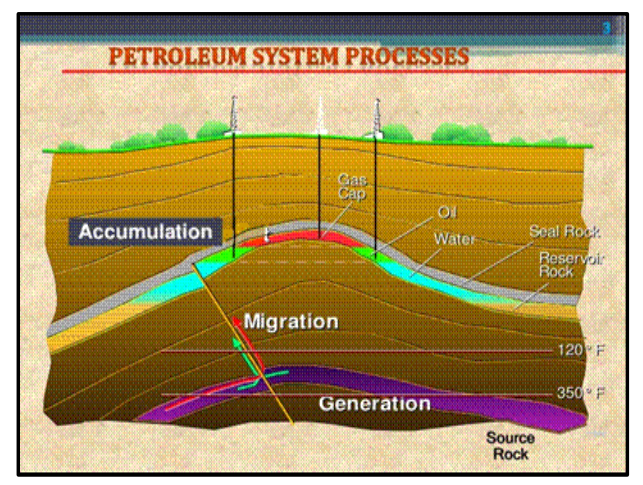

Gambar 2.1 Petroleum System

\section{Source Rock}

Merupakan endapan sedimen yang mengandung bahan-bahan organik yang cukup untuk dapat menghasilkan minyak dan gas bumi ketika endapan terbeut tertimbun dan terpanaskan, dan dapat mengelurakan minyak dan gas bumi tersebut dalam jumlah yang ekonomis. Bahan organik yang terkandung disebut kaorgen. Karogen memiliki 4 tipe yaitu:

a. Tipe 1

Alga dari lingkungan pengendapan lacustrine dan lagoon. Tipe seperti ini dapat mengahsilkan minyak dengan kualitas baik dan mampu menghasilkan gas.

b. Tipe 2

Campuran dari tumbuhan dan mikroorganisme laut. Tipe seperti ini merupakan bahan utama minyak dan gas bumi karena banyak terdapat zat organik penyusun.

c. Tipe 3

Tanaman darat dalam endapan yang mengandung batubara. Tipe seperti ini umumnya menghasilkan gas dan sedikit minyak karena kandungannya.

d. Tipe 4

Bahan bahan tanaman yang teroksidasi. Tipe seperti ini tidak mampu menghasilkan minyak dan gas.

\section{Reservoir Rock}

Batuan yang mampu menyimpan dan mampu mengalirkan hidrokarbon. Diman batuan tersebut harus memiliki porositas sebagai penyimpan hidrokarbon dan permibilitas sebagai tempat megalirnya hidrokarbon.

\section{Migrasi}

Proses transportasi minyak dan gas dari batuan sumber menuju Reservoir. Dalam transportasi hidrokarbon terjadi beberapa proses yaitu: 
- Migrasi Primer : Migrasi dalam sekuen dari source rock

- Ekspulsion : Dari sekuen Source Rock menuju carrier bed

- Migrasi Sekunder : Transportasi carrier bed menuju ke trap

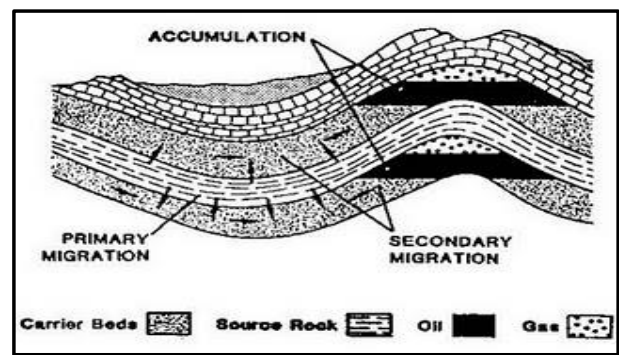

Gambar 2.2 Migrasi

\section{Trap (Perangkap)}

Proses migrasi dan pembentukan trap tidak saling berhubungan dan terjadi di waktu yang berbeda. Waktu pembentukan trap sangat penting karena jika trap terbentuk sebelum hidrokarbon bermigrasi maka kemungkinan akan ditemukanya akumulasi hidrokarbon didalam trap dan jika sebaliknya maka kemungkinan hidrokarbon telah melewati trap tersebut. Adapun tipe jebakan yaitu:

a. Perangkap Struktur

Prinsip perangkap struktural merupakan perangkap yang paling orisinil dan sampai dewasa ini merupakan perangkap yang paling penting. Pada perangkap struktur terdapat berbagai unsur perangkap yang membentuk lapisan penyekat di reservoir sehingga dapat menjebak minyak, hal ini disebabkan gejala tektonik atau struktur, misalnya pelipatan dan patahan, kedua hal ini merupakan unsur utama dalam pembentukan perangkap, sedemikian sehingga minyak tidak dapat lagi kemana- mana.

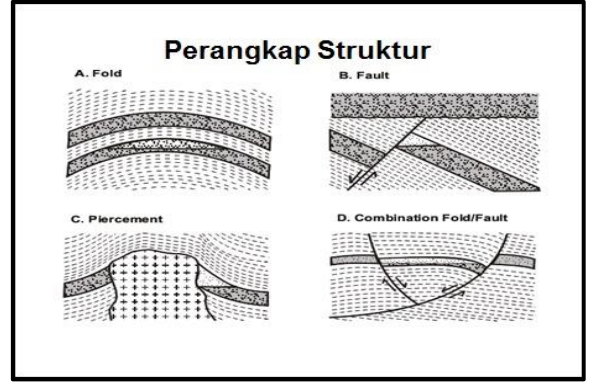

Gambar 2.3 Perangkap Struktur

b. Perangkap Stratigrafi

Prinsip perangkap statigrafi adalah minyak dan gas terjebak dalam perjalananya keatas, terhalang dari segala arah terutama dari bagian atas dan pinggir, karena batuan reservoir menghilang atau berubah fasies menjadi batuan lain atau batuan yang karakteristik reservoir menghilang sehinnga merupakan penghalang permeabilitas. Perangkap ini dipengaruhi oleh variasi perlapisan secara vertikal dan lateral, perubahan facies batuan dan ketidakselarasan dan variasi lateral dalam litologi pada suatu lapisan reservoir dalam perpindahan minyak bumi (hidrokarbon).

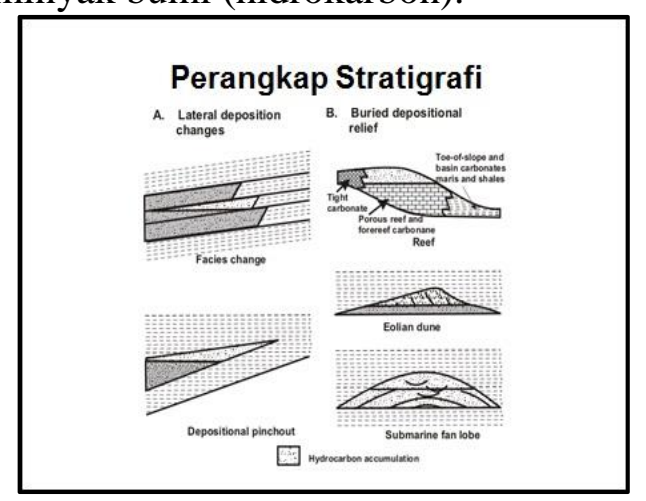

Gambar 2.4 Perangkap Statigrafi

c. Perangkap Kombinasi

Perangkap reservoir kebanyakan merupakan kombinasi perangkap struktur dan perangkap statigrafi dimana setiap unsur struktur merupakan faktor bersama dalam membatasi bergeraknya minyak dan gas. Beberapa kombinasi antara unsur 
statigrafi dan unsur struktural adalah sebagai berikut:

1. Kombinasi antara lipatan dengan pembajian

Kombinasi lipatan dengan pembajian dapat terjadi karena salah satu pihak, pasir menghilang dan dilain pihak hidung antiklin menutup arah lainnya. Maka jelaslah hal ini sering terjadi pada perangkap statigrafi normal.

2. Kombinasi antara patahan dan pembajian

Kombinasi antara pemajian dengan patahan jauh lebih biasa dari pada pembajian yang terdiri sendiri. Kombinasi ini dapat terjadi karena terapat suatu kemiringan wilayah yang membatasi bergeraknya ke suatu arah dan di arah lain ditahan oleh adanya suatu patahan dan pada arah lainnya lagi di tahan oleh pembajian.

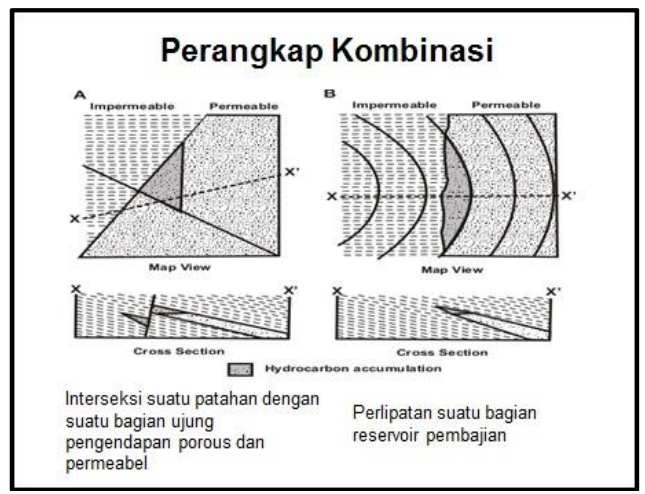

Gambar 2.5 Perangkap Kombinasi

\section{Seal ( Penutup)}

Seal (penutup) merupakan sistem batuan penyekat yang memiliki porositas dan permeabilitas yang kecil sebagai batuan penutup agar hidrokarbon tidak bermigrasi lagi dan terakumulasi di suatu tempat.

\subsection{Karakteristik Batuan dan \\ Fluida Reservoir}

Reservoir adalah suatu tempat terakumulasinya minyak dan gas bumi. Pada umumnya reservoir minyak memiliki karakteristik yang berbedabeda tergantung dari komposisi, temperatur dan tekanan pada tempat dimana terjadi akumulasi hidrokarbon didalamnya. Suatu reservoir minyak biasanya mempunyai tiga unsur utama yaitu adanya batuan reservoir, lapisan penutup dan perangkap. Proses penganalisisan tekanan transien di reservoir berhubungan erat dengan mekanisme batuan dan fluidanya yang memiliki karakteristik yang berbedabeda. Sebelum mempelajari konsep dari pengujian sumur terlebih dahulu perlu diketahui prinsip dasar dari sifatsifat fisik batuan dan fluida reservoir yang mempengaruhi penganalisisan tekanan transien di reservoir.

\subsubsection{Sifat Fisik Batuan Reservoir}

Reservoir minyak adalah suatu lapisan geologi dibawah permukaan bumi yang mempunyai bentuk struktur sedemikian rupa sehingga minyak terakumulasi di reservoir dalam jumlah yang besar. Biasanya lapisan tersebut tertutup oleh suatu lapisan batuan yang tidak permeable (cap rock), dan berbentuk perangkap yang dapat menjebak minyak. Reservoir minyak pada umumnya memiliki karakteristik yang berbeda-beda, tergantung pada komposisi, temperatur dan tekanan tempat dimana terjadinya akumulasi fluida hidrokarbon di dalam reservoirnya.

\section{Porositas}

Porositas merupakan ukuran perbandingan antara volume pori batuan dengan volume total batuan persatuan volume tertentu.

$$
\begin{aligned}
\phi & =\frac{V_{b}+V_{g}}{V_{b}}=\frac{V_{p}}{V_{b}} \\
& =\frac{V_{p}}{V_{g}+V_{p}} \times 100 \%
\end{aligned}
$$


Dimana :

$\mathrm{V}_{\mathrm{b}}=$ volume batuan total (Bulk Volume)

$\mathrm{V}_{\mathrm{g}}=$ volume butiran total (Grain Volume)

$\mathrm{V}_{\mathrm{p}}=$ volume pori batuan total

$\phi=$ porositas, fraksi (\%)

Gambar ilustrasi media berpori diperlihatkan pada gambar 2.6 dibawah ini. Adapun faktor utama yang menyebabkan variasi harga porositas antara lain: sudut kemiringan, bentuk dan ukuran butiran, komposisi mineral pembentuk batuan.

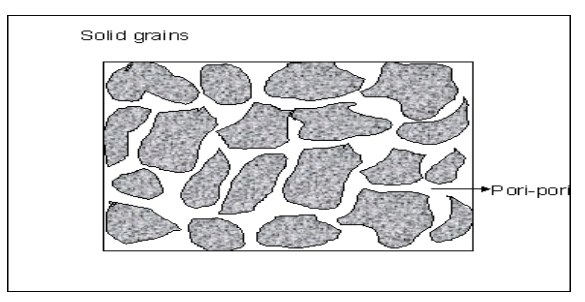

Gambar 2.6 Ilustrasi Media Berpori

Persamaan yang di atas menggambarkan variasi susunan dari packing batuan yang memiliki butiran (spheres) dengan diameter yang dianggap sama. Dengan perhitungan sederhana berdasarkan geometris batuan menunjukkan besarnya porositas terhadap beberapa variasi susunan packing butiran, secara berturut-turut, untuk cubic sebesar $47,6 \%$, untuk hexagonal sebesar 39,5\% dan untuk rhombohedral sebesar 25,9\%. Untuk masing-masing kemungkinan variasi packing tersebut, ukuran butiran tidak mempengaruhi porositas karena butiran dianggap seragam. Kecuali untuk sandstone yang mempunyai ukuran butiran yang tidak seragam dan mempunyai material penyemenan antar butiran yang mengurangi volume pori batuan. Porositas dapat diklasifikasikan menjadi dua bagian yaitu porositas absolut dan efektif. Pada proses pembentukan dari ruang-ruang kosong dalam batuan, ada pori-pori yang saling berhubungan (interconnected) dan ada yang tidak saling berhubungan (inconnected). Oleh sebab itu, ada 2 pengertian tentang porositas, yaitu:

1. Porositas absolut, adalah perbandingan volume pori-pori total terhadap volume batuan total (bulk volume).

2. Porositas efektif, adalah perbandingan volume pori-pori yang saling berhubungan terhadap volume batuan total (bulk volume).

$\phi_{\text {eff }}=\frac{\text { Volume pori yang berhubungan }}{\text { Volume total batuan }} \times 100 \%$

Berdasarkan asal kejadiannya, porositas dapat dibagi atas porositas primer (Original) dan porositas sekunder (Induced). Porositas primer adalah porositas yang terjadi pada saat proses pengendapan batuan terjadi, contohnya sandstone dan limestone. Pada sandstone ditandai dengan hubungan yang intergranular, sedangkan pada batuan limestone dicirikan oleh hubungan butiran yang interkristalin dan bentuk oolit atau bulat-bulat. Porositas sekunder adalah porositas batuan yang terbentuk sesudah batuan sedimen terendapkan. Porositas sekunder biasanya tidak mempunyai hubungan dengan proses sedimentasi dan dicirikan dengan ruang-ruang karena pelarutan, rekahan, celah, sesar dan proses dolomitasi. Porositas batuan reservoir dapat diklasifikasikan sebagai berikut :

Tabel 2.1 Klasifikasi Porositas

\begin{tabular}{|c|c|}
\hline Porositas (\%) & Kualitas \\
\hline $0-5$ & Jelek Sekali \\
\hline $5-10$ & Jelek \\
\hline $10-15$ & Sedang \\
\hline $15-20$ & Baik \\
\hline$>20$ & Sangat Bagus \\
\hline
\end{tabular}




\section{Permeabilitas}

Permeabilitas adalah sifat dari media berpori dan ukurannya yang menyatakan kemampuan media tersebut (batuan) untuk melewatkan fluida. Apabila media berpori tidak saling berhubungan, maka batuan tersebut tidak memiliki permeabilitas. Oleh karena terdapat hubungan antara permeabilitas batuan dengan porositas efektif batuan maka semua faktor yang berpengaruh terhadap porositas juga akan berpengaruh terhadap permeabilitas, misalnya ukuran butir batuan, ukuran kekompakan batuan, distribusi pori batuan dan sebagainya. Dasar penentuan permeabilitas batuan adalah hasil percobaan yang dilakukan oleh Henry Darcy pada tahun 1856. Dalam percobaan ini, Henry Darcy menggunakan batu pasir tidak kompak yang dialiri air. Dari hasil eksperimen yang dilakukan Darcy didapatkan persamaan umum Darcy sebagai berikut:

$$
Q=\frac{k \cdot A}{\mu} x \frac{d P}{d L}
$$

Dimana :

Q = Laju alir fluida, cc / det

$\mathrm{k} \quad=$ Permeabilitas, darcy

$\mu \quad=$ Viskositas, $\mathrm{cp}$

$\mathrm{dP} / \mathrm{dL}=$ Gradien tekanan dalam arah aliran, $\operatorname{dim} / \mathrm{cm}$

A $=$ luas penampang, $\mathrm{cm}^{2}$

Permeabilitas menurut

pengertiannya terbagi 3 , yaitu :

- Permeabilitas absolut, adalah kemampuan batuan reservoir untuk melewatkan aliran fluida satu fasa atau disaturasi $100 \%$ oleh salah satu, misalnya hanya minyak atau gas saja.

- Permeabilitas efektif, adalah kemampuan batuan untuk melewatkan aliran fluida yang lebih dari satu fasa, misalnya minyak dan air, air dan gas, gas dan minyak atau ketiga-tiganya.

- Permeabilitas relatif, adalah perbandingan antara permeabilitas efektif kondisi saturasi tertentu dengan permeabilitas absolut. Hubungannya dapat dilihat sebagai berikut:

$$
K_{r e l}=\frac{K_{e f f}}{K_{a b s}}
$$

Dimana :

$\mathrm{K}_{\text {rel }}=$ Permeabilitas Relevan

$\mathrm{K}_{\mathrm{eff}}=$ Permeabilitas Effisien

$\mathrm{K}_{\mathrm{abs}}=$ Permeabilitas Absolute

\section{Saturasi}

Saturasi adalah perbandingan antara volume pori-pori batuan yang terisi fluida formasi tertentu terhadap total volume pori-pori batuan yang terisi fluida atau jumlah kejenuhan fluida dalam batuan reservoir per satuan volume pori. Oleh karena didalam reservoir terdapat tiga jenis fluida, maka saturasi dibagi menjadi tiga yaitu saturasi air $\left(S_{w}\right)$, saturasi minyak $\left(S_{o}\right)$ dan saturasi gas $\left(S_{g}\right)$.

Didalam kenyataan, fluida reservoir tidak dapat diproduksi semuanya. Hal ini disebabkan adanya saturasi minimum fluida yang tidak dapat diproduksi lagi atau disebut dengan irreducible saturation sehingga berapa besarnya fluida yang diproduksi dapat dihitung dalam bentuk saturasi.

4. Tekanan Kapiler (Pc)

Tegangan permukaan yang terjadi didalam media berpori antara fluida dan batuan maupun antar fluida, dimana besarnya tegangan pada permukaan pori-pori batuan yang menghasilkan tekanan dikenal dengan Tekanan Kapiler. Tekanan Kapiler pada suatu batuan berpori didefinisikan sebagai perbedaan tekanan antara fluida yang membasahi batuan dengan fluida yang bersifat tidak membasahi 
batuan jika didalam media berpori tersebut terdapat dua atau lebih fluida tidak tercampur dalam kondisi statis.

Dimana :

$$
\mathrm{Pc}=\mathrm{P}_{\mathrm{nm}}-\mathrm{P}_{\mathrm{w}}
$$

$\mathrm{P}_{\mathrm{c}}=$ Tekanan kapiler, dyne $/ \mathrm{cm}^{2}$

$\mathrm{P}_{\mathrm{nw}}=$ Tekanan pada permukaan fluida non wetting-phase, dyne $/ \mathrm{cm}^{2}$

$\mathrm{P}_{\mathrm{w}}=$ Tekanan pada permukaan fluidawetting-phase, dyne $/ \mathrm{cm}^{2}$

\section{Wettability}

Wettability di definisikan sebagai kecenderungan dari suatu fluida untuk menyebar atau melekat kepermukaan batuan dengan adanya fluida tak tercampur lainnya. Sebuah cairan fluida akan bersifat membasahi bila gaya adhesi antara batuan dari partikel cairan lebih besar dari pada gaya kohesi antar partikel cairan itu sendiri.

\section{- Wetting-Phase Fluid}

Fluida pembasah biasanya akan mudah membasahi permukaan batuan, tetapi karena adanya gaya tarik menarik antara batuan dan fluida, fasa pembasah akan mengisi ke pori-pori yang lebih kecil dulu dari batuan berpori. Fasa fluida pembasah umumnya sangat sukar bergerak kereservoir hidrokarbon.

\section{- Non Wetting-Phase Fluid}

Non wetting-phase fluid sukar membasahi permukaan batuan. Dengan adanya gaya tolak antar batuan dan fluida menyebabkan Non wettingphase fluid akan menempati sebagian besar pori batuan dan pada umumnya sangat mudah bergerak.

Batuan reservoir umumnya water wet, dimana air akan membasahi permukaan batuan. Kondisi water wet dimana gaya adhesi bernilai positif $(+)$ dan sudut kontaknya antara $0^{\circ} \leq 0 \leq$ $90^{\circ}$, apabila $0=0^{\circ}$, maka batuan dianggap "strongly water wet". Batuan reservoir oil wet jika fasa minyak membasahi permukaan batuan gaya adhesi bernilai sudut kontaknya antara $90^{\circ} \leq 0 \leq 180^{\circ}$, apabila $0=180^{\circ}$, maka batuannya dianggap strongly oil wet.

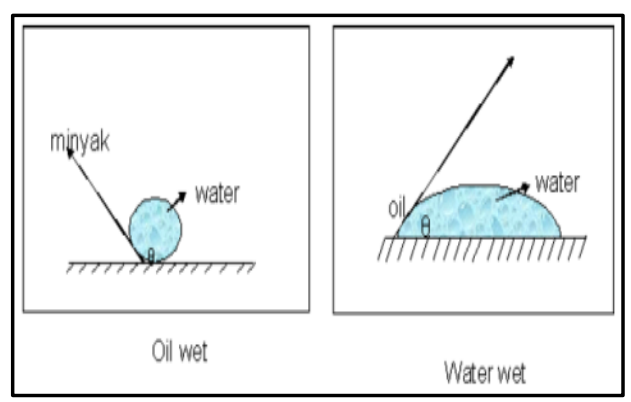

Gambar 2.7 Wettability Batuan

\subsubsection{Sifat-Sifat Fluida Reservoir}

Fluida yang umumnya terdapat dalam reservoir terbagi tiga fasa yaitu gas, minyak dan air, dan secara normal dari material-material yang terkandung dalam fluida dapat diperkirakan bentuk suatu fasa fluida apakah minyak, gas atau cairan. Minyak bumi terbentuk dari berbagai macam sifat-sifat gabungan senyawa hidrokarbon yang rumit, serta gas-gas yang terlarut di dalamnya.

Minyak bumi yang diperoleh dari tiap-tiap lapangan mempunyai karakteristik yang berbeda, ini menunjukkan hidrakorban yang menyusun minyak bumi tersebut berlainan satu terhadap lainnya.

- Densitas Minyak $\left(\rho_{\text {oil }}\right)$

Densitas minyak merupakan perbandingan antara massa minyak terhadap volume pada kondisi tekanan dan temperatur tertentu.

$$
\rho_{o=\frac{m}{v}}
$$

Dimana :

$$
\begin{array}{ll}
\rho_{o} & =\text { Densitas minyak }(\mathrm{gr} / \mathrm{cc}) \\
\mathrm{m} & =\text { Massa minyak }(\mathrm{gr}) \\
\mathrm{v} & =\text { Volume minyak }(\mathrm{cc})
\end{array}
$$


- Spesifik Gravity (SG)

Spesifik gravity merupakan perbandingan dari suatu fluida minyak terhadap densitas air, yang diukur pada kondisi tekanan atmosfer (60 F). Untuk industri minyak satuan yang umum digunakan adalah Spesifik Gravity atau API Gravity.

$$
\begin{gathered}
S G=\frac{\rho_{o}}{\rho_{w}} \\
S G=\frac{141,5}{A P I+131,5}
\end{gathered}
$$

Dimana:

$\mathrm{SG}=$ Spesifik Gravity

$\rho_{o}=$ Densitas Minyak, $1 \mathrm{bm} / \mathrm{cuft}$

$\rho_{w}=$ Densitas Air, lbm/cuft

- Viskositas

Merupakan

besarnya

keengganan fluida untuk mengalir yang merupakan fungsi dari tekanan dan temperatur. Fluida yang berviskositas besar akan sulit untuk mengalir dari pada fluida dengan viskositas yang kecil.

\subsection{Well Service}

Well Service merupakan suatu bagian yang bertugas menangani segala kegiatan yang berhubungan dengan sumur. Kegiatan tersebut meliputi usaha agar sumur siap berproduksi (initial completion) maupun usaha perbaikan sumur akibat kerusakan saat berproduksi (work over). Semua kegiatan yang dilakukan oleh team ini bertujuan untuk mempertahankan serta meningkatkan laju produksi sumur. Well Service dibagi dalam beberapa bagian yaitu :

1. Tool House adalah bagian yang bertugas dalam menyediakan dan memelihara segala peralatan sehingga dapat selalu siap pakai.

2. Operation adalah bagian yang melaksanakan pemasangan artificial lift serta memperbaiki kerusakan yang ada pada sumur-sumur.
3. Transport Well Service adalah bagian yang memperlancar pekerjaan well service dengan selalu menyediakan transport untuk mengantarkan segala peralatan yang saat melakukan service terhadap sumur. Pekerjaan yang dilakukan oleh divisi ini dibagi dalam 4 kelompok kerja yaitu : initial completion, service, work over dan equipment maintenance.

Dalam penelitian ini Penulis menganalisis bahwa kegiatan Bailing out sand termasuk dalam kegiatan transport well service.

\subsection{Sand Bailer / Sand Pump}

Metode Bailing out sand suatu proses pengeluaran pasir yang terdapat dalam sumur, dinding casing yang dapat menutup formasi sumur dan dinding casing. Dimana alat ini berbentuk barrel yang dirangkai dengan tubing dan dimasukkan ke dalam lubang sumur dengan rangkaian tubing atau wireline dan sampai kedalaman yang di inginkan dan setelah barrel penuh berisi pasir, rangkaian tubing atau wireline diangkat ke permukaan, selanjutnya pasir dibersihkan di permukaan, begitu seterusnya sampai tinggi pasir di bawah lubang perforasi. Semua operasi cabut masuk rangkaian tubing dan wireline menggunakan work over rig.

Adapun peralatan peralatan yang digunakan pada Bailing out sand yaitu :

- Scrapper

- Sand pump

- Depthtometer

- Bailer box

\subsection{Sucker Rod Pump}

Pengoperasian Pumping

Unit (Sucker Rod Pump) merupakan salah satu teknik pengangkatan buatan yang digunakan untuk membantu mengangkat minyak dari dasar sumur ke permukaan tanah 
sampai ke tangki penampungan. Metoda ini digunakan karena penurunan energi alami atau tekanan reservoir sumur tersebut sudah tidak mampu lagi mengangkat minyak ke permukaan.

Prinsip kerja Pumping Unit yaitu mengubah gerak rotasi dari Prime Mover menjadi gerak naik turun oleh sistem Pitman Crank Assembly, kemudian gerak naik turun ini melalui walking beam di teruskan ke Horse Head di jadikan gerak lurus naik turun (Up Stroke dan Down Stroke) untuk menggerakan plunger melalui rangkaian rod.

\section{METODOLOGI PENELITIAN}

\subsection{Waktu dan Tempat Penelitian}

Penelitian yang berjudul tentang

"Perbandingan Hasil Produksi Sumur FA \#17 Sebelum dan Setelah Well Service dengan Menggunakan metode Bailing Out Sand di PT Pertamina Hulu Energi Siak Field Batang", dilaksanakan pada 1-31 Maret 2019 yang bertempat di PT Pertamina Hulu Energi Siak Field Batang.

\subsection{Metode Penulisan}

Adapun metode yang digunakan dalam penelitian ini merupakan pendekatan secara deskriptif. Pendekatan deskriptif adalah metode yang bertujuan memberi gambaran terhadap suatu objek dengan cara meneliti, mengolah data, menganalisis serta menginterpretasikan hal yang ditulis dengan pembahasan yang teratur dan sistematis yang bertujuan untuk memecahkan masalah yang dihadapi pada waktu sekarang ini.

\section{Studi Literatur}

Studi literatur dilakukan dengan cara mengumpulkan dan mempelajari literatur serta segala sesuatu yang ada kaitannya dengan objek yang diteliti dan dapat menunjang pembuatan laporan Penelitian ini sehingga dapat mempertegas teori dan keperluan analisis serta mendapatkan data yang sebenarnya. Dengan demikian Penulis dapat mengetahui secara pasti dan jelas mengenai permasalahan-permasalahan yang ada untuk kemudian dicari solusi pemecahannya. Studi pustaka ini dilakukan pada beberapa referensi untuk mendukung penelitian secara keilmuwan sehingga dalam pembahasannya akan ditunjang dengan dasar-dasar teori yang kuat.

2. Observasi Lapangan

Observasi dari kegiatan lapangan merupakan pengambilan data secara langsung, yang di lakukan oleh Penulis dengan mendatangi lokasi pengambilan data, yaitu kantor dan lapangan PT Pertamina Hulu Energi Siak Field Batang.

\section{Diskusi}

Teknik pengambilan data dengan mengadakan komunikasi secara langsung dengan pembimbing lapangan serta melakukan diskusi dengan supervisor production yang ada di PT Pertamina Hulu Energi Siak Field Batang. Diskusi yang dilakukan meliputi pengolahan data, diskusi mengenai materi yang tidak dipahami serta analisis pengolahan data dengan demikian Penulis dapat mengetahui mengenai permasalahan yang ada dan mendapatkan solusi dari permasalahan tersebut.

\subsection{Tahap Pengumpulan Data}

Dalam tahapan pengumpulan data Penulis mendapatkan data lapangan yang terdiri dari data primer dan sekunder meliputi:

a. Data Primer

Data primer merupakan data yang diperoleh dari data produksi sumur yang meliputi karakteristik resevoir yaitu laju alir, temperatur, dan data lainnya. 
b. Data Sekunder

Data Sekunder merupakan data yang diambil dari file yang ada di komputer unit data, yang meliputi data hasil dari hasil perbandingan produksi sebelum dan setelah Well Service menggunakan metode Bailing out sand. Sejarah sumur meliputi kegiatan apa saja yang pernah dilakukan pada sumur tersebut serta data struktur geologi dari lapangan tersebut dan data pendukung lainnya.

\subsection{Tahapan Pengolahan Data}

\subsubsection{Menghitung Kapasitas Sand Pump}

Evaluasi keberhasilan hasil laju produksi dengan metode Bailing out sand, menggunakan alat sand pump yang mana fungsinya untuk menghisap scale, pasir dan fluida.

$\mathrm{V}=\pi \times \mathrm{r}^{2} \times \mathrm{t}$

Di mana :

$$
\begin{array}{ll}
\mathrm{V} & =\text { Volume sand pump }, \mathrm{cm}^{3} \\
\pi & =3,14 \\
\mathrm{r} & =\text { Jari-jari sand pump yang } \\
& \text { digunakan, } \mathrm{cm} \\
\mathrm{t} & =\text { panjang sand pump, } \mathrm{cm}
\end{array}
$$

3.4.2. Evaluasi Berdasarkan Kurva Inflow Relationship (IPR)

Kurva IPR menunjukkan gambaran kualitatif yang menyatakan produksi suatu sumur, dimana dengan menggambarkan hubungan antara tekanan alir dasar sumur dengan laju produksi. Dalam hal ini akan digunakan perhitungan IPR dua fasa pada saat dilakukan stimulasi untuk mengetahui perubahan laju alir sebelum dan setelah diakukannya Well Service Bailing out sand.

Adapun langkah yang dilakukan dalam pembuatan kurva IPR yaitu:

6. Siapkan data perhitungan IPR, yaitu $\mathrm{P}_{\mathrm{r}}, \mathrm{P}_{\mathrm{wf}}$, dan $\mathrm{Q}$ baik sebelum maupun setelah Bailing out sand.
7. Lalu asumsi $\mathrm{P}_{\mathrm{wf}}$ pada saat sebelum dan setelah Bailing out sand dan juga hitung $\mathrm{Q}$ pada asumsi $\mathrm{P}_{\mathrm{wf}}$ tersbut dengan persamaan :

$$
\mathrm{Q}=\frac{Q \max }{1-0.2\left(\frac{P w f}{P r}\right)-0.8\left(\frac{P w f}{P r}\right)^{2}}
$$

Dimana :

$\mathrm{P}_{\mathrm{wf}}=$ Tekanan alir dasar sumur (psi)

$\operatorname{Pr} \quad=$ Tekanan reservoar $(\mathrm{psi})$

$\mathrm{Q}=$ Laju produksi (bbl/d)

8. Kemudian Plot tekanan sumur $\left(\mathrm{P}_{\mathrm{wf}}\right)$ terhadap laju alir (Q) baik untuk sebelum maupun setelah Bailing out sand.

9. Lihat perubahan laju alir produksi dan lakukan analisis.

\subsubsection{Evaluasi Berdasarkan Productivity Index (PI)}

Productivity Index merupakan indeks yang menyatakan kemampuan suatu sumur untuk berproduksi pada suatu kondisi tertentu. Bailing out sand juga dapat dikatakan berhasil apabila terjadi kenaikan Productivity index(PI) setelah dilakukan Well Service.

Adapun langkah perhitungannya di antaranya :

$\checkmark$ Dari data yang telah tersedia untuk perhitungan IPR, Masukkan nilai laju alir (Q) serta tekanan reservoir $\left(\mathrm{P}_{\mathrm{r}}\right)$ dan tekanan sumur $\left(\mathrm{P}_{\mathrm{wf}}\right)$ ke dalam persamaan :

$$
\mathrm{PI}=\frac{Q}{P s-P w f}, \mathrm{bbl} / \mathrm{d} / \mathrm{psi}
$$

$$
\begin{aligned}
& \text { Dimana: } \\
& \mathrm{PI}=\text { Productivity Index }(\mathrm{bbl} / \mathrm{d} / \mathrm{psi}) \\
& \mathrm{Q}=\text { Laju alir }(\mathrm{bbl} / \mathrm{d}) \\
& \mathrm{P}_{\mathrm{s}}=\text { Tekanan reservoar }(\mathrm{psi}) \\
& \mathrm{P}_{\mathrm{wf}}=\text { Tekanan dasar sumur }(\mathrm{psi})
\end{aligned}
$$


Kermit E Brown (1967) memberikan batasan terhadap tingkat PI, yaitu:

a. Jika PI < 0,5 maka PI dinyatakan rendah atau buruk

b. Jika $0,5<\mathrm{PI}<1,5$ maka PI dinyatakan sedang

c. Jika PI > 1,5 maka PI dinyatakan tinggi atau baik

$\checkmark$ Lakukan perhitungan PI untuk sebelum dan setelah dilakukannya Bailing out sand.

$\checkmark$ Kemudian dari hasil PI dapat dianalisis apakah kegiatan Bailing out sand tersebut berhasil atau tidak.

\section{HASIL DAN PEMBAHASAN}

Beberapa Sumur di Lapangan Batang dengan indikasi intensitas well service yang tinggi. Fenomena FNCO (Fluid Not Coming Out) di Lapangan Batang sangat sering terjadi dengan riwayat intensitas pekerjaan perawatan sumur paling tinggi adalah Bailing Out Sand (BOS) akibat kepasiran.

Bailing Out Sand merupakan proses pengeluaran pasir yang terdapat di dalam sumur dan di dinding casing yang dapat menutup formasi di dalam sumur dan di dinding casing.

\subsection{Data Spesifikasi Sucker Rod Pump Sumur FA \#17}

Sumur FA \#17 memakai metode pengangkatan buatan berupa Sucker Rod Pump. Dapat diketahui jenis pompa pumping unit Sumur FA \#17 yaitu : C114-119-86 dimana huruf C menunjukkan tipe Conventional, kedalaman polished rod string 119 lbs dengan panjang length atau stroke length 86 inch.

Tabel 4.1 Data Sucker Rod Pump Sumur FA \#17

\begin{tabular}{|c|c|c|c|c|c|c|c|c|c|}
\hline \multirow[b]{2}{*}{ No. } & \multirow[b]{2}{*}{ Location } & \multirow[b]{2}{*}{ Well Status } & \multicolumn{7}{|c|}{ Pumping Unit } \\
\hline & & & Serial Number & Structure & Type & $\begin{array}{c}\text { Gear Box } \\
\text { Brand }\end{array}$ & $\begin{array}{c}\text { Wristpin } \\
\text { Bearing } \\
\text { Type }\end{array}$ & \begin{tabular}{|c|} 
Tail Bearing \\
Type
\end{tabular} & $\begin{array}{c}\text { Saddle } \\
\text { Bearing } \\
\text { Type }\end{array}$ \\
\hline 1 & BTG \#05 & & P777435 & Lufkin & C114-119-86 & Lufkin & 4SF & 3RA & $4 T G$ \\
\hline
\end{tabular}

\subsection{Perhitungan Kapasitas Sand}

Pump

Berikut perhitungan kapasitas sand pump yang digunakam untuk mengangkat pasir, scale, maupun crude oil :

$$
\mathrm{V}=\pi \times \mathrm{r}^{2} \times \mathrm{t}
$$

Dimana :

$\mathrm{V}=$ Volume sand pump, $\mathrm{cm}^{3}$

$\pi=3,14$

$\mathrm{r}=$ Jari-jari sand pump yang

digunakan, $\mathrm{cm}$

$\mathrm{t}=$ Panjang sand pump, $\mathrm{cm}$
Perhitungan kapasitas sand pump yang di gunakan pada Sumur FA \#17 sebagai berikut :

$\mathrm{V}=3,14 \times 1,75^{2}$ inch $\times 10 \mathrm{~m}$

$=3,14 \times 4,44^{2} \mathrm{~cm} \times 1000 \mathrm{~cm}$

$=61900,704 \mathrm{~cm}^{3}$

$=61,900$ Liter 


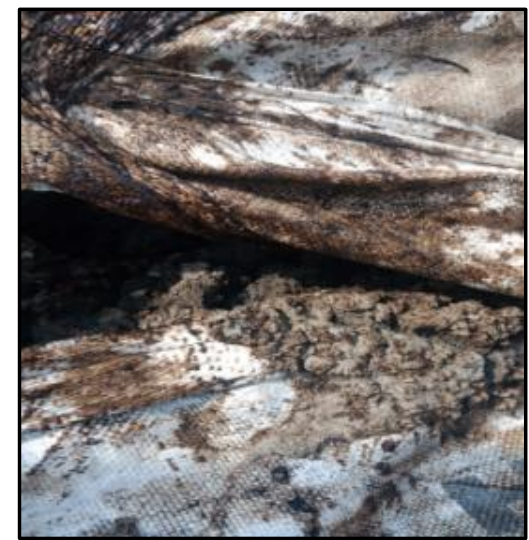

Gambar 4.1 Pasir yang Terangkat Di Dalam Sand Pump

\subsection{Langkah-langkah Kegiatan Bailing Out Sand}

Dalam mengevaluasi masalah kepasiran ini terlebih dahulu melakukan kegiatan pencabutan atau pengangkatan peralatan produksi yang ada di dalam sumur dan di atas permukaan sehingga keadaan posisi sumur tinggal casing. Kegiatan ini agar memperoleh atau mengetahui collapse atau suatu peristiwa kejadian yang ada di dalam sumur. Adapun langkah-langkah sebelum kegiatan Bailing Out Sand di laksanakan adalah sebagai berikut:

$\checkmark$ Moving in rig up

$\checkmark$ Cabut horse head

$\checkmark$ Cabut polished rod

$\checkmark$ Buka $x$ mastree

$\checkmark$ Cabut donat yang berada di well head

$\checkmark$ Pasang BOP

$\checkmark$ Cabut rangkaian string

$\checkmark$ Persiapan angkat tubing

$\checkmark$ Setelah itu keadaan sumur hanya menyisakan casing di dalamnya.

\subsection{Peralatan-Peralatan Yang Digunakan Pada Bailing Out Sand}

Adapun peralatan-peralatan yang digunakan pada Bailing out sand yang ada di PT Pertamina Hulu Energi Siak Field Batang.

\subsubsection{Scrapper}

Fungsi utama dari Scrapper adalah membersihkan Scale, pasir, karat yang ada di dinding casing.

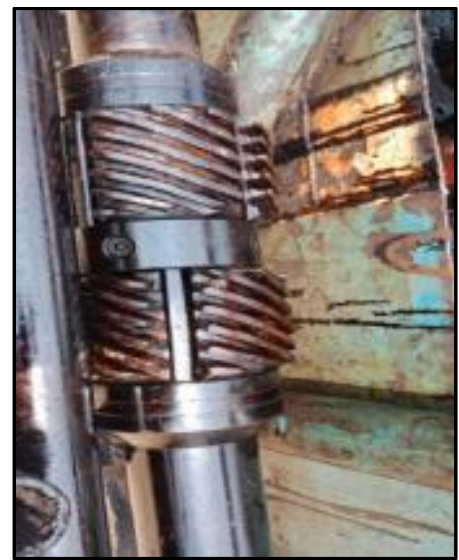

Gambar 4.2 Scrapper

\subsubsection{Sand Pump}

Fungsi utama dari Sand Pump yaitu mengeluarkan pasir, crude oil, air yang terdapat di dalam sumur produksi agar dapat proses produksi berjalan dengan lancar atau produksi tidak tersumbat. Di dalam sand pump ini terdapat rangkaian yaitu piston, rabber dan lidah-lidah untuk menghisap pasir, crude oil dan air.

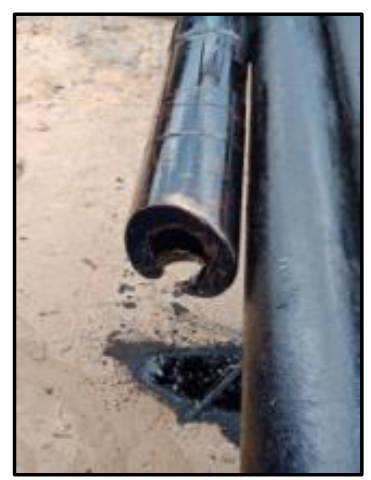

\section{Gambar 4.3 Sand Pump}

\subsubsection{Depthtometer}

Fungsi utama dari Depthtometer yaitu alat ukur untuk 
Sand Pump untuk mengetahui keberadaan Sand Pump hingga masuk ke dalam sumur.

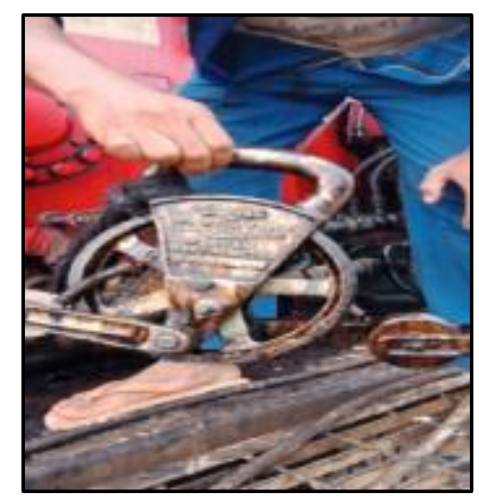

Gambar 4.4 Depthtometer

\subsubsection{Bailer box}

Fungsi utama dari Bailer box yaitu tempat pembuangan hasil dari bailing out sand, isinya berupa pasir, crude oil, air, scale.

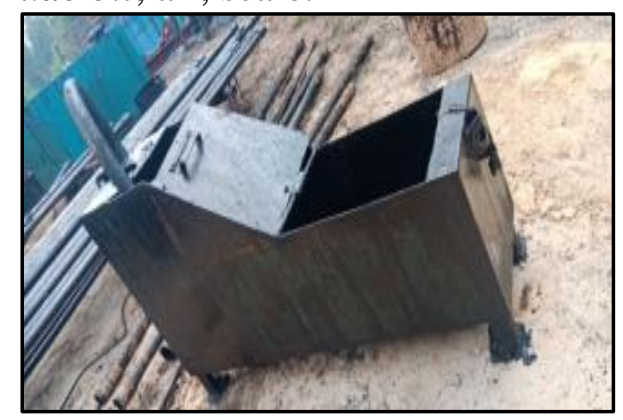

Gambar 4.5 Bailer Box

\subsection{Langkah-Langkah \\ Pengoperasian Sand Pump}

Di dalam sand pump ini terdapat rangkaian yaitu piston Sand Pump yaitu fungsinya untuk mengeluarkan pasir, scale, crude oil dan air yang terdapat di dalam sumur produksi agar dapat proses produksi berjalan dengan lancar atau produksi tidak tersumbat.

Adapun langkah-langkah pengoperasian Sand pump di PT Pertamina Hulu Energi Siak Field Batang yaitu :
1. Alat Sand Pump dimasukkan kedalam sumur hingga pasir terhisap ke dalam Sand pump

2. Kemudian Sand pump di shake sampai 3X memastikan bahwa pasir, scale, crude oil yang ada di dalam sumur tadi sudah terhisap ke dalam sand pump

3. Setelah itu Sand pump yang ada di dalam sumur tadi di keluarkan hingga ke atas permukaan, kemudian pasir, scale, crude oil yang ada di dalam Sand pump tadi di letakkan ke Bailer Box.

Pada rangkaian sand pump ini terdapat rangkaian yaitu piston, rubber dan lidah-lidah untuk menghisap pasir, scale, crude oil dan air. Pengoperasian Sand Pump di PT Pertamina Hulu Energi Siak Field Batang dioperasikan selama 24 jam hingga Well Service Selesai. Karena untuk terus memenuhi kebutuhan sumur dan untuk kebutuhan produksi serta kebutuhan lainnya, maka dari itu PT Pertamina Hulu Energi Siak Field Batang memiliki 2 unit Sand Pump yang memiliki ukuran panjang $30 \mathrm{ft}$, diameter 3-1/2" dan 2-7/8". Tetapi yang sering banyak digunakan yaitu ukuran 3-1/2" karena kapasitas 31/2" besar dari pada Sand Pump ukuran 2-7/8" dengan kapasitas ukurannya kecil.

\subsection{Evaluasi Masalah Kepasiran Bailing out sand \\ Evaluasi ini dilakukan dengan} tujuan untuk mengetahui tingkat keberhasilan ataupun kegagalan dari pelaksanaan Well Service Bailing out sand yang telah dilakukan terhadap produktivitas sumur. Dalam evaluasi produksi ini, parameter yang digunakan untuk mengevaluasi pekerjaan Well Service yaitu dilihat dari segi produksinya seperti laju produksi dan 
Productivity Index (PI) serta perubahan kurva IPR sebelum dan setelah Well Service.

\subsubsection{Evaluasi Berdasarkan Test Laju Produksi}

Evaluasi berdasarkan test laju produksi ini untuk melihat peningkatan produksi yang terjadi setelah pelaksanaan Well Service. Dimana evaluasi masalah kepasiran berdasarkan test laju produksi dilihat atau mengacu pada data produksi sumur FA \#17 sebelum dan setelah dilakukan Well Service.

Berikut hasil data produksi berdasarkan test laju produksi sumur FA \#17 sebelum dan setelah di lakukan Well Service.

Tabel 4.2 Data Produksi Sebelum Dan Setelah Well Service

\begin{tabular}{|l|c|c|c|}
\hline Data Produksi & $\begin{array}{c}\text { Sebelum Well } \\
\text { Service }\end{array}$ & $\begin{array}{c}\text { Setelah Well } \\
\text { Service }\end{array}$ & Satuan \\
\hline Gross & 138,6 & 159,2 & BFPD \\
\hline Minyak & 76,24 & 90,71 & BOPD \\
\hline Air & 62,38 & 68,43 & BWPD \\
\hline Water cut & 45 & 43 & $\%$ \\
\hline
\end{tabular}

Berdasarkan data produksi dari hasil test laju produksi yang ada, baik dari jumlah gross, minyak, air dan water cut, pada Well Service ini terjadi kenaikan produksi dari sebelum dan sesudah dilakukan Well Service yaitu Gross mengalami kenaikan menjadi 159,2 BFPD, minyak sebesar 90,71 BOPD, air sebesar 68,43 BWPD, lalu watercut-nya mengalami penurunan $43 \%$ sehingga dapat dikatakan berhasil karena untuk produksi gross, minyak dan airnya mengalami peningkatan sedangkan untuk watercut-nya sendiri

\begin{tabular}{|c|c|c|c|}
\hline Parameter & $\begin{array}{c}\text { Sebelum } \\
\text { Well } \\
\text { Service }\end{array}$ & $\begin{array}{c}\text { Setelah } \\
\text { Well } \\
\text { Service }\end{array}$ & Satuan \\
\hline $\mathrm{P}_{\mathrm{r}}$ & 213,9 & 213,9 & Psi \\
\hline $\mathrm{P}_{\mathrm{wf}}$ & 183,08 & 197,294 & Psi \\
\hline $\mathrm{Q}_{\mathrm{act}}$ & 138,6 & 159,2 & $\mathrm{Bfpd}$ \\
\hline
\end{tabular}

mengalami penurunan.
4.6.2 Evaluasi Berdasarkan Kurva Inflow Performance Relationship (IPR)

Kurva Inflow Performance Relationship (IPR) menunjukkan gambaran kemampuan dari suatu formasi untuk berproduksi, dimana dengan menggambarkan hubungan antara tekanan sumur dengan laju produksi. Evaluasi hasil Bailing out sand dengan kurva IPR ini dilakukan yaitu dengan membandingkan kurva IPR sebelum dan setelah Well Service untuk mengetahui hasil dari pelaksanaan Bailing out sand. Berikut adalah data produksi dan proses perhitungan untuk mendapatkan gambaran dari kurva IPR.X

Tabel 4.3 Parameter Perhitungan IPR 
a). Perhitungan menentukan $Q_{\max }$ (laju alir maksimal)

$$
\begin{aligned}
& \frac{Q}{1-0.2\left(\frac{P w f}{P r}\right)-0.8\left(\frac{P w f}{P r}\right)^{2}} \\
& =\frac{138.6}{1-0.2\left(\frac{183,08}{213,9}\right)-0.8\left(\frac{183,08}{213,9}\right)^{2}} \\
& =570,9667 \mathrm{bpd}
\end{aligned}
$$

b). Kemudian asumsikan $\mathrm{P}_{\mathrm{wf}}$ dan $\mathrm{Q}$ untuk mendapatkan gambaran IPR

- Menghitung nilai $Q$ pada $P_{w f}$ asumsi $=200 \mathrm{psi}$

$\mathrm{Q}=\mathrm{Q}_{\max }\left[1-0.2\left(\frac{p w f}{p r}\right)-0.8\left(\frac{p w f}{p r}\right)^{2}\right]$

$570,9667\left[1-0.2\left(\frac{200}{213,9}\right)-0.8\left(\frac{200}{213,9}\right)^{2}\right]$

64,85739 bpd.

Tabel 4.4 Nilai Asumsi $P_{w f}$ Dan $Q$ Sebelum Di Well Service

\begin{tabular}{|c|c|}
\hline $\mathrm{P}_{\mathrm{wf}}(\mathrm{psi})$ & $\mathrm{Q}(\mathrm{bpd})$ \\
\hline 213,9 & 0 \\
\hline 200 & 64,85739 \\
\hline 150 & 266,2603 \\
\hline 136,62 & 311,6896 \\
\hline 50 & 519,315 \\
\hline 0 & 570,9667 \\
\hline
\end{tabular}

\subsubsection{Setelah di Well Service}

a) Perhitungan menentukan $Q_{\max }$ (laju alir maksimal)

$$
\begin{aligned}
& \frac{Q}{1-0.2\left(\frac{P w f}{P r}\right)-0.8\left(\frac{P w f}{P r}\right)^{2}} \\
& =\frac{159,2}{1-0.2\left(\frac{197,294}{213,9}\right)-0.8\left(\frac{197,294}{213,9}\right)}
\end{aligned}
$$$$
\mathrm{Q}_{\max }=
$$

$=1179,956 \mathrm{bpd}$.

b). Kemudian asumsikan $\mathrm{P}_{\mathrm{wf}}$ dan $\mathrm{Q}$ untuk mendapatkan gambaran IPR

- Menghitung nilai $\mathrm{Q}$ pada $\mathrm{P}_{\mathrm{wf}}$ asumsi $=200 \mathrm{psi}$

$\mathrm{Q}=\mathrm{Q}_{\max }\left[1-0.2\left(\frac{p w f}{p r}\right)-0.8\left(\frac{p w f}{p r}\right)^{2}\right]$ $1179,95\left[1-0.2\left(\frac{200}{213,9}\right)-0.8\left(\frac{200}{213,9}\right)^{2}\right]$

134,0339 bpd.

Tabel 4.5 Nilai Asumsi $P_{w f}$ Dan Q Setelah di Well Service

\begin{tabular}{|c|c|}
\hline $\mathrm{P}_{\mathrm{wf}}(\mathrm{psi})$ & $\mathrm{Q}(\mathrm{bpd})$ \\
\hline 213,9 & 0 \\
\hline 200 & 134,0339 \\
\hline 150 & 550,252 \\
\hline 122,406 & 735,7794 \\
\hline 50 & 1073,213 \\
\hline 0 & 1179,956 \\
\hline
\end{tabular}

\subsubsection{Plot Grafik IPR}

Setelah melihat dan melakukan perhitungan untuk menentukan grafik kurva IPR, selanjutnya plot grafik dari asumsi $\mathrm{P}_{\mathrm{wf}}$ dan nilai $\mathrm{Q}$ yang sebelum dan setelah Bailing out sand atau Well Service untuk mengetahui perbedaan yang terjadi. Hasil kurva IPR sebelum dan setelah Well Service pada Gambar 4.6

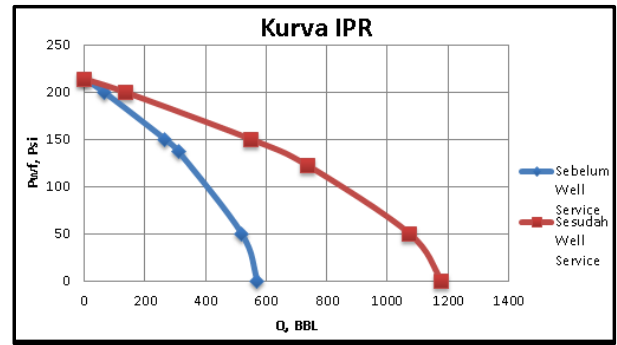

Gambar 4.6 Kurva IPR Sebelum dan Setelah Well Service

\subsubsection{Data Produksi}

Data produksi ini diambil pada ${ }^{2}$ saat proses produksi berlangsung dari sebelum dilakukannya pelaksanaan Well Service pada sumur produksi dan setelah dilakukan Bailing out sand di saat sumur mulai produksi kembali. Sehingga kita dapat membandingkan hasil produksi setelah pelaksanaan Well Service dan Bailing out sand.

Dari gambar 4.7 pada tanggal 23 Juni 2016 Gross senilai 138,6 BFPD 
dan setelah itu dilakukan kegiatan Well Service dan mulai diproduksi pada tanggal 07 Juli 2016 dengan nilai Gross sebesar 159,2 BFPD.

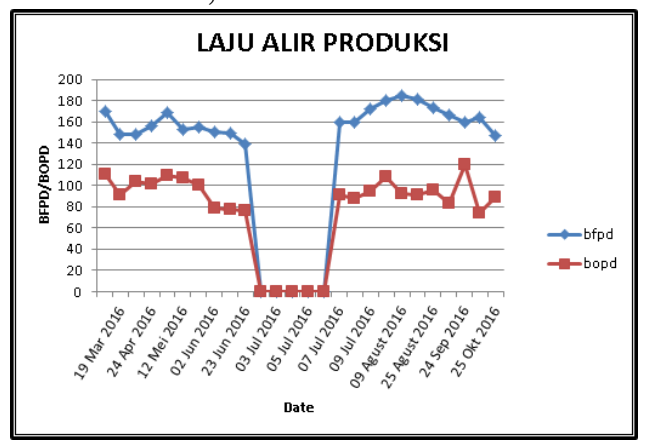

\section{Gambar 4.7 Grafik Production Performance}

\subsubsection{Evaluasi Berdasarkan Productivity Index (PI) Productivity Index (PI)} merupakan suatu nilai yang menyatakan kemampuan sumur untuk berproduksi. Dimana secara umum nilai untuk productivity Index

akan mengalami peningkatan setelah dilakukannya Well Service. Dalam perhitungan nilai Productivity Index parameter yang digunakan yaitu tekanan sumur $\left(\mathrm{P}_{\mathrm{wf}}\right)$, tekanan reservoir $\left(\mathrm{P}_{\mathrm{r}}\right)$ dan laju produksi $(\mathrm{Q})$. Berikut nilai Productivity Index sebelum dilakukan kegiatan Well Service :

$$
\begin{gathered}
P I=\left[\frac{Q}{\operatorname{Pr}-P w f}\right] \\
=\left[\frac{138,6}{213,9-183,08}\right] \\
=4,497 \mathrm{bbl} / \mathrm{psi} .
\end{gathered}
$$

Sebelum dilakukan kegiatan well service nilai Productivity Index (PI) Sumur FA \#17 sebesar 4,497 $\mathrm{bbl} / \mathrm{psi}$, sedangkan setelah dilakukan

Tabel 4.6 Laju Alir Optimum Terhadap Efisiensi Pompa

\begin{tabular}{|c|c|c|c|c|c|c|}
\hline Eff & $80 \%$ & $70 \%$ & $60 \%$ & $50 \%$ & $40 \%$ & $30 \%$ \\
\hline Q Opt & 943,965 & 825,9694 & 707,9738 & 589,9781 & 471,9825 & 353,9869 \\
\hline Qw Opt & 405,905 & 355,1668 & 304,4287 & 253,6906 & 202,9525 & 152,2144 \\
\hline $\mathrm{P}_{\mathrm{wf}}$ & 80 & 105 & 120 & 149 & 170 & 180 \\
\hline Q Oil Opt & 538,0601 & 470,8026 & 403,545 & 336,2875 & 269,03 & 201,7725 \\
\hline
\end{tabular}

kegiatan well service nilai Productivity Index $(P I)$ sebagai berikut :

$$
\begin{aligned}
P I & =\left[\frac{Q}{\operatorname{Pr}-P w f}\right] \\
& =\left[\frac{159,2}{213,9-197,294}\right] \\
& =9,586 \mathrm{bbl} / \mathrm{psi} .
\end{aligned}
$$

Berdasarkan perhitungan $P I$ dengan metode Vogel, setelah di lakukan kegiatan well service nilai productivity Index (PI) Sumur FA \#17 menjadi $9,586 \mathrm{bbl} / \mathrm{psi}$.

\subsubsection{Analisis Laju Alir Optimum Pada Sumur FA \#17}

Analisis dilakukan dengan menentukan persentase efisiensi yang akan dipasang pada pompa. Dari efisiensi tersebut dilakukan perhitungan terhadap laju alir optimum yang terpasang pada pompa. Data hasil perhitungan laju alir optimum terhadap efisiensi pompa yang terpasang dapat dilihat pada tabel 4.6 di bawah : 
- Menghitung Laju Alir Optimum Terhadap Efisiensi Pompa pada Sumur FA\#17 :

$$
\begin{aligned}
\mathrm{Q}_{\text {opt }} @ 80 \% & =\mathrm{Q}_{\max } \times 80 \% \\
& =1179,956 \times 80 \% \\
& =943,965 \mathrm{bfpd} .
\end{aligned}
$$

- Menghitung Laju Produksi Water terhadap Efisiensi Pompa pada Sumur FA \#17 :

$$
\begin{aligned}
\mathrm{Q}_{\mathrm{w}} @ 80 \% & =\mathrm{Q}_{\mathrm{opt}} @ 80 \% \text { x \% WC } \\
& =943,965 \mathrm{bfpd} \times 43 \% \\
& =405,905 \mathrm{bwpd} .
\end{aligned}
$$

- Menghitung Laju Alir Minyak terhadap Efisiensi Pompa pada Sumur FA \#17 :

$$
\begin{aligned}
\mathrm{Q}_{\text {oil }} @ 80 \% & =\mathrm{Q}_{\text {opt }} @ 80 \% \text { x Oil Cut } \\
& =943,965 \text { bfpd x 57\% } \\
& =538,0601 \text { bopd. }
\end{aligned}
$$

Efisiensi pompa Sucker Rod Pump pada Sumur FA \#17 ini lebih dianjurkan sebesar 60\%. Hal ini dikarenakan potensi sumur yang masih baik yang dapat dilihat dari nilai PI yang cukup besar yaitu 9,586 bbl/psi. Dari pemasangan efisiensi pompa sebesar $60 \%$ dapat di lihat di tabel bahwa tekanan dasar sumur $\left(\mathrm{P}_{\mathrm{wf}}\right)$ yang dipasang sebesar 120 Psi dan sumur tersebut akan menghasilkan fluida sebanyak 707,9738 BFPD.

\subsection{Analisis Keberhasilan kegiatan Well service}

Untuk mengetahui peningkatan produksi dan keberhasilan, dilakukan analisis akhir produksi sebelum dan setelah Well service dengan kurva IPR sebagai berikut :

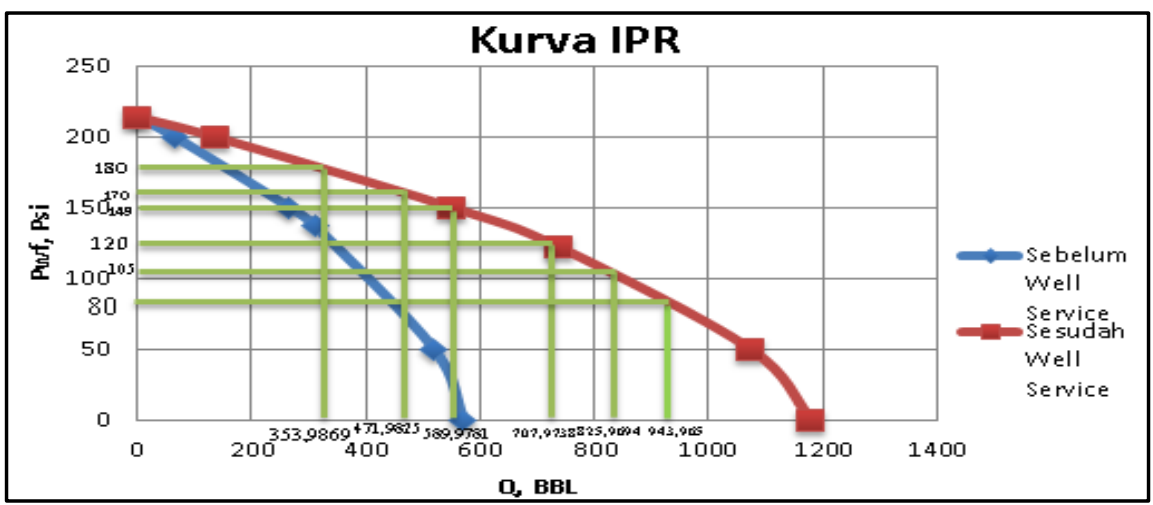

\section{Gambar 4.8 Produksi Sebelum dan Setelah well service dengan Kurva IPR}

Sebelum kegiatan well service di lakukan di dapatlah data berdasarkan hasil Plot $\mathrm{P}_{\mathrm{wf}}$ vs $\mathrm{Q}$ pada kurva IPR, di peroleh nillai dari $\mathrm{Q}_{\text {act }}$ sebesar 138,6 bfpd, $Q_{\max } 570,9667$ bpd. Kemudian di dapat laju alir fluida sebesar $138,6 \mathrm{bfpd}$ dan laju alir minyak sebesar 76,24 bopd dan untuk PI-nya 4,497 bbl/psi.
Setelah kegiatan Well Service dilakukan terjadi perubahan disetiap parameternya yaitu dengan laju alir fluida sebesar 159,2 bfpd dan laju alir minyak sebesar 90,71 bopd. Dilihat dari hasil Plot $\mathrm{P}_{\mathrm{wf}}$ vs $\mathrm{Q}$ pada kurva IPR, diperoleh nilai $Q_{\text {act }}$ sebesar 159,2 bfpd dan Qmax sebesar 1179,956 bpd. Lalu 
untuk PI menjadi 9,586 bbl/psi, sehingga pekerjaan kegiatan well service ini dapat dikatakan berhasil karena dari beberapa aspek tersebut mengalami peningkatan.

Sumur FA\#17 dianjurkan untuk melakukan pemasangan efisiensi pompa sebesar 60\%. Hal ini dikarenakan nilai PI sumur yang 9,586 $\mathrm{bbl} / \mathrm{psi}$ menandakan bahwa sumur ini meiliki potensi yang sangat baik, sehingga sumur ini dapat menunjang produksi. Dari pemasangan efisiensi pompa sebesar $60 \%$ dapat di lihat pada tabel 4.6 bahwa tekanan dasar sumur $\left(\mathrm{P}_{\mathrm{wf}}\right)$ yang di pasang sebesar 120 Psi dan sumur tersebut akan menghasilkan fluida sebanyak 707,9738 BFPD.

\section{PENUTUP}

\subsection{Kesimpulan}

Berdasarkan nilai dari hasil perbandingan produksi Sumur FA \#17 Sebelum Dan Setelah Well Service Dengan Menggunakan Metode Bailing Out Sand Di PT Pertamina Hulu Energi Siak Field Batang maka di ambil kesimpulan sebagai berikut :

1. Proses dan cara kerja metode bailing out sand pada kegiatan well service dimulai dengan memasukkan alat scrapper untuk membersihkan pasir,scale, yang ada di dinding casing setelah itu masuk alat sand pump untuk mengangkat atau menghisap pasir, maupun endapanendapan, yang telah di bersihkan dari scrapper tersebut. Setelah itu pasir maupun endapan-endapan tersebut di angkat ke permukaan dan di buang ke bailer box tempat penampung sementara.

2. Kapasitas sand pump yang digunakan pada Sumur FA\#17 sebesar 61,900 Liter.
3. Sebelum kegiatan well service dapat di ketahui hasil produksi laju alir fluida sebesar 138,6 bfpd dan laju alir minyak sebesar 76,24 bopd. Dilihat dari hasil Plot $\mathrm{P}_{\mathrm{wf}}$ vs Q pada kurva IPR, diperoleh nilai $\mathrm{Q}_{\text {act }}$ sebesar 138,6 BFPD dan $\mathrm{Q}_{\max }$ Sebesar 570,9667 bpd. Sementara dari hasil kegiatan setelah well service dapat diketahui hasil produksi laju alir fluida sebesar 159,2 bfpd dan laju alir minyak sebesar 90,71 bopd. Dilihat dari hasil Plot $\mathrm{P}_{\mathrm{wf}}$ vs $\mathrm{Q}$ pada kurva IPR, diperoleh nilai $Q_{\text {act }}$ sebesar 159,2 BFPD dan $\mathrm{Q}_{\max }$ sebesar 1179,956bpd. Sehingga pekerjaan kegiatan well service ini dapat dikatakan berhasil karena dari beberapa aspek tersebut mengalami peningkatan. Dan juga pada Sumur FA\#17 dianjurkan untuk melakukan pemasangan efisiensi pompa sebesar 60\% karena dilihat pada tabel 4.6 bahwa tekanan dasar sumur $\left(\mathrm{P}_{\mathrm{wf}}\right)$ yang dipasang sebesar 120 Psi dan sumur tersebut akan menghasilkan fluida sebanyak 707,9738 BFPD.

\section{DAFTAR PUSTAKA}

Brown, K.E. 1967. The Technology Of Artificial Lift Method. Petroleum Publishing Co : USA

Darling, T.. 2005. Well Service, USA : Elsevier.

Fatma Petroleum. 2011 Teknik Produksi, Judul : Sand Bailer Sub judul : Penanggulangan Masalah Kepasiran

Koesumadinata R.P.. 1980.'Geologi Minyak dan Gas Bumi, Edisi-2 Jilid 1 dan 2'.'Bandung : ITB 
Press.

Pedoman Pertamina. 2017 Teknik

Produksi, Judul : Solusi

Penanganan Masalah Pasir 